\title{
NUMERICAL MODELLING OF RUTFORD ICE STREAM, ANTARCTICA (Abstract)
}

\author{
by
}

\section{R.M. Frolich}

(British Antarctic Survey, Natural Environment Research Council, High Cross, Madingley Road, Cambridge CB3 OET, U.K.)

and

\section{D.R. MacAyeal}

(Department of Geophysical Sciences, University of Chicago, Chicago, IL 60637, U.S.A)

A two-dimensional finite element model has been applied to Rutford Ice Stream, Antarctica, and part of Ronne Ice Shelf into which the ice stream flows. The model is an extension of one describing ice-shelf flow, and relies on vertical shear in the ice stream being small in some mathematically defined sense. This is equivalent to requiring the vertical shear to be confined to a basal layer or a deformable substrate.

Although there is no direct observational evidence for such a layer beneath Rutford Ice Stream, extensive surface surveys and estimates of the strength of the overlying ice show that some dynamically equivalent mechanism must occur. If basal shear stress is parameterised in terms of the thickness and viscosity of a linearly viscous substrate, as may be the case beneath Ice Stream B in Antarctica, then going upstream from the grounding line, the thickness of this layer must decrease, and the viscosity increase (to retain a realistic thickness at the upstream limit), in order to reproduce the observed surface velocities. This physically reasonable picture is currently adopted as a working hypothesis.
Vertical shear in the body of the ice stream appears to be negligible for approximately $70 \mathrm{~km}$ above the grounding line. Sensitivity tests show that, in this lower section, iceshelf back stress is an important restraining influence. A $10 \%$ reduction in back stress would produce an immediate $15 \%$ increase in grounding line flux. Further upstream, however, higher surface slopes and slightly lower surface velocities suggest that the neglect of vertical shear may be less appropriate. The effect of a reduction in ice-shelf back stream is not felt in this region immediately, as the gravitational driving force is almost balanced by local basal shear traction.

A complex surface morphology has been revealed by satellite imagery below the grounding line of Rutford Ice Stream. On the basis that this may be evidence of time dependent behaviour, the finite element model is being used to investigate the origin of the pattern. Ice-shelf back stress, basal melting, mass flux from tributary glaciers and substrate properties can all be varied in physically realistic ways to try to reproduce, qualitatively, the observed surface morphology.

\section{ANNUALLY-AVERAGED POLAR SEA-ICE EXTENTS DURING 1978-1987: NORTHERN EXTENT DECREASE AND SOUTHERN EXTENT OSCILLATION}

(Abstract)

by

Per Gloersen

(Laboratory for Oceans, NASA Goddard Spaceflight Center, Greenbelt, MD 21146, U.S.A.)

and

William J. Campbell

(Ice and Climate Project, U.S. Geological Survey, University of Puget Sound, Tacoma, WA 98416, U.S.A.)

Recently reported observations of a nine-year decrease in global sea-ice extent, obtained from the Scanning Multichannel Microwave Radiometer onboard the Nimbus-7 satellite during 1978-87 and averaged with an annual running mean, have been separated into Arctic and Antarctic components. The annually-averaged global extent decrease was $2.5 \%$. Here it is shown that the greater part of this decrease occurred in the Arctic where there was a decline of $3.5 \%$ with a goodness of fit of 0.54 .
Superimposed on this decline was a small oscillation with a period of about four years and an amplitude of about $1 \%$. A significantly smaller and statistically insignificant decrease of $1.2 \%$ with a goodness of fit of 0.03 is observed in the annually averaged Antarctic sea-ice extent. However, three large oscillations with amplitudes of about $4 \%$ and periods of about three years occurred in phase with three El Niño events. 